\title{
Caminhos para o bem-estar docente através da contação de histórias
}

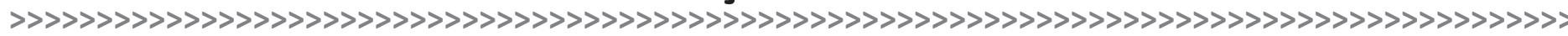

\author{
Janaina Cé Rossoni* \\ Denise Regina Quaresma da Silva**
}

\section{Resumo:}

Este artigo versa sobre o bem-estar docente e objetiva refletir sobre a contribuição da contação de histórias no desencadeamento de situações promotoras de motivação e satisfação. A abordagem metodológica é de cunho qualitativo, descritivo, pautando-se no relato de três oficinas oferecidas a docentes e graduandos/as da cidade de Canoas/ RS. Nossa reflexão leva em consideração pressupostos teóricos advindos dos estudos de Nóvoa (2007), Pocinho e Capelo (2009), Sampaio, Stobäus, Mosquera e Jesus (2012), entre outros. A partir dos relatos dos/as participantes, é possível constatar que o sentimento de mal-estar não permeia a fala dos/as graduandos/as do curso de Letras, porém faz-se presente no discurso de professores atuantes na rede pública. Percebemos que a contação de histórias, direcionada às histórias pessoais, alheias e coletivas, promove um desencadeamento de estratégias de produção de sentidos e, consequentemente, situações de bem-estar docente.

\section{Palavras-chave:}

Bem-estar. Contação de histórias. Docência.

\begin{abstract}
:
This paper talks about the teacher's well-being and aims to reflect on the contribution of storytelling in situations that promote motivation and satisfaction. The methodological approach is descriptive and qualitative, based on the report of three workshops offered to teachers and undergraduate students, in Canoas/RS. Our reflection considers the theoretical studies from Nóvoa (2007), Pocinho and Capelo (2009), Sampaio, Stobäus, Mosquera and Jesus (2012), among others. From the reports of the participants it is possible to see that the speech of Languages students do not include discomfort syndrome, however it exists on the speech of active teachers in public schools. We realize that the act of storytelling, when directed to the collective and personal stories or other people's stories, promotes strategies that trigger the production of meaning and, consequently, the well-being of teacher.
\end{abstract}

\section{Keywords:}

Well-being. Storytelling. Teaching. 


\section{Introdução}

O mal-estar docente é um assunto que tem suscitado muitos questionamentos e pesquisas acadêmicas. Estudos ${ }^{3}$ apontam a emergência de novos olhares sobre a profissão docente perante as mudanças sociais contemporâneas que acarretam "fardos" 4 difíceis de serem carregados, transportados e desvencilhados da condição de ser professor/a.

Nesse ínterim, as doenças advindas de situações de mal-estar são, geralmente, vistas como senso comum, isto é, o mercado aposta em livros de autoajuda, em medicamentos farmacêuticos promotores do milagre da recuperação. Contudo, pouco fala-se ao professor/a de sua professoralidade, de sua condição de sujeito da educação com seus direitos e deveres (COSTA, 2005; NÓVOA, 2007; AGUIAR JR., 2010). Ao contrário, a mídia lida com essas questões às avessas, noticiando, muitas vezes, o lado negativo da profissão docente, $\mathrm{o}$ que desencadeia a desmotivação profissional e a consequente carência de novos docentes.

Estudos apontam que o descaso com a docência pode ocorrer também nas próprias instituições de ensino, quando os gestores educacionais não propiciam condições favoráveis ao exercício das funções, e/ou situações de diálogo, de manifestações sobre angústias, ansiedades e preocupações (NÓVOA, 2007a; TEIXEIRA, 2007; TIMM; STOBÄUS; MOSQUERA, 2010; SAMPAIO; STOBÄUS; MOSQUERA; JESUS, 2012).

A demanda de trabalho absorve os docentes, e pouco se faz em termos de atividades de autoestima e autoimagem, tão importantes ao processo de subjetivação e ao cuidado de si e dos outros. A valorização precária dos professores/as diante de tantos afazeres acarreta decepções e um repensar constante sobre a carreira profissional. Cotidianamente escutamos relatos de desistência e de abandono que cercam o dia a dia de tantos profissionais da educação, os quais, solitariamente, carregam estes sentimentos. Também defrontamo-nos com muitos profissionais que, infelizmente, já abandonaram a docência. Outros tantos ainda continuam em salas de aula como meros figurantes de um contexto reducionista $\mathrm{e}$ fragmentado (COSTA, 2005; TEIXEIRA, 2007; AGUIAR JR., 2010).

Diante dessa problemática, tratada na Formação Continuada de Professores da Rede Municipal de Canoas/RS, propomos a realização de duas oficinas objetivando a ressignificação do ensino com a contação de histórias. Ministramos, também, uma oficina para graduandos/as do Curso de Letras, na ocasião do evento Semana Acadêmica promovido por uma Instituição de Ensino Superior (IES) de Canoas/RS.

A partir da escuta das múltiplas vozes que ecoaram nas oficinas sobre a arte e o encantamento do ato de contar histórias, e a produção de sensações de bem-estar que o compartilhamento de histórias pessoais, alheias e coletivas possibilita, descreveremos o trabalho realizado e proporemos uma reflexão sobre o tema.

\section{Fundamentando o enredo: o bem-estar docente e a contação de histórias}

As oficinas que norteiam este trabalho versaram sobre a contação de histórias. Este termo provém de um neologismo da Língua Portuguesa, referente ao ato de contar/narrar histórias, no qual há a presença de um contador/narrador que dá corpo e voz às narrativas.

$3>$ Conforme o trabalho Efeitos de um programa de apoio ao bem-estar docente na construção pessoal e profissional, apresentado na IX ANPED SUL 2012

4 > Expressão utilizada por Costa (2005) para se referir às cargas que podem acompanhar a atividade docente.
Em inglês, storytelling é o termo correspondente para contação de histórias e há muitos estudos referentes a essa técnica desenvolvida em escolas americanas na qual está presente o 'coração', ou seja, o lado afetivo do processo educativo (COLLINS e COOPER, 2005).

A definição de contação de histórias/storytelling não obedece a padronizações. Os estudiosos e profissionais do assunto a conceituam conforme suas visões e experiências, ou seja, de forma subjetiva. Os autores Collins e Cooper (2005) a definem desta forma: 
Definir contação de histórias ou contador de histórias é tentar concretizar o que é abstrato. É suficiente dizer que a contação de história está entre as formas mais antigas de comunicação. Ela existe em todas as culturas. Contação de história é comum a todos os seres humanos, em todos os lugares, em todos os tempos. Ela é usada para educar, inspirar, recordar eventos históricos, entreter, transmitir hábitos culturais ${ }^{5}$. (COLLINS; COOPER, 2005, p. 1).

O olhar dado à contação de histórias nas práticas realizadas, quer seja a contação de narrativas orais (oriundas de experiências individuais ou coletivas), quer seja a de narrativas impressas, não dispensou o caráter estético e artístico dessa modalidade literária. Pelo contrário, foi através do encantamento proveniente das histórias pessoais e alheias que as professoras e os/as estudantes se envolveram de forma interativa e emocional.

Segundo Collins e Cooper (2005, p. 4): “O conhecimento narrativo é experiencial e adquirido culturalmente. Ele é o melhor meio disponível para os estudantes organizarem suas experiências e compreenderem a si mesmos". Assim, o contar e o ouvir histórias promovem processos de identificação com o outro e consigo mesmo, um repensar sobre as experiências de vida, sobre as escolhas do passado e as expectativas e perspectivas futuras. As histórias dirigem a atenção dos ouvintes devido ao seu caráter envolvente, já que há um misto de curiosidade e ansiedade para saber como será resolvido o conflito/ problema ou como será o final da história.

Benjamin (1994) trata da natureza experimental das histórias, uma vez que o cerne de sua filosofia é a 'experiência' produtora de narrativas espontâneas. O autor escreve que a arte de narrar está em processo de extinção, pois os indivíduos já não sabem narrar devidamente uma história. Como causas do empobrecimento das narrativas, ele traz: as mudanças sociais, como a distância entre os grupos humanos, sobretudo, quanto às gerações; o desaparecimento do artesanato como organização pré-capitalista que permitia tempo para contar, conectando a mão, a voz, a palavra e o gesto; e, em consequência das duas causas anteriores, o enfraquecimento da narração como transmissora de sabedoria.

No texto O narrador, Benjamin (1994, p. 198) chama a arte de narrar de "[...] a faculdade de intercambiar experiências [...]" e caracteriza os narradores como indivíduos de senso prático, referindo-se assim à narrativa:

\footnotetext{
Ela tem sempre em si, às vezes de forma latente, uma dimensão utilitária. Essa utilidade pode consistir seja num ensinamento moral, seja numa sugestão prática, seja num provérbio ou numa norma de vida - de qualquer maneira, o narrador é um homem que sabe dar conselhos. Mas, se 'dar conselhos' parece hoje algo de antiquado, é porque as experiências estão deixando de ser comunicáveis. (BENJAMIN, 1994, p. 200).
}

Portanto, as constatações de Benjamin vêm ao encontro das mudanças sociais contemporâneas. Uma vez que a contação de histórias seja resgatada, ora nas escolas, ora nas famílias, pode haver um reestabelecimento das experiências narrativas e, dessa forma, um resgate de tradições culturais, de fontes de sabedoria e de trocas mútuas. Professores/ as e estudantes ao interagirem com suas próprias histórias ou com as construídas coletivamente, ou ainda, com histórias alheias, podem ressignificar suas experiências, as quais muitas vezes são comuns a todos, todavia, não são compartilhadas.

As oficinas realizadas com graduandos e docentes tiveram por objetivo mostrar às/aos participantes a contribuição da contação de histórias para as práticas escolares, como um subsídio para auxiliar o/a professor/a nas tarefas educativas. O enfoque dado ao tema diz respeito às técnicas e ao caráter transformador deste ato comunicativo. Em um primeiro momento, não havia o intuito de se observar o bem ou o mal-estar docente,
5 > Tradução livre de: To define storytelling or storyteller is to try to make concrete that which is abstract. Suffice it to say that storytelling is among the oldest forms of communication. It exists in every culture. Storytelling is the commonality of all human beings, in all places, in all times. It is used to educate, to inspire, to record historical events, to entertain, to transmit cultural mores. 
mas sim de perceber como a contação de histórias estava sendo abordada ou vista pelos professores em suas atividades pedagógicas.

No entanto, durante o desenvolvimento das oficinas, foi possível perceber o quanto as/os docentes necessitavam de um carinho, de uma atenção, ou melhor, de uma proposta motivadora para seguirem adiante, para acreditarem em si mesmas/os, percebendo-se como sujeitos da educação.

A fim de fundamentar as articulações pretendidas entre os relatos obtidos durante as práticas sobre a contação de histórias e as situações de bem-estar docente, iniciamos o 'enredo' deste trabalho postulando alguns conceitos importantes.

Pocinho e Capelo (2009) têm lançado novos olhares para a condição docente, sobretudo, a respeito de estratégias de coping ${ }^{6}$, intervenções e reflexões na tentativa de propiciar condições que conduzam ao bem-estar do/a educador/a. Dessa forma, as autoras sugerem algumas estratégias utilizadas por professores/as não vulneráveis ao stress, os/as quais apresentam níveis mais elevados de eficácia, iniciativa e persistência em relação aos/ as demais docentes, diante dos problemas diários. Dentre as estratégias, as autoras fazem referência a três dimensões: as de controle ou confronto; as de escape ou evitamento e as de gestão de sintomas.

As primeiras dizem respeito a estratégias de visão mais otimista, como discutir a situação, falar com outras pessoas envolvidas, ver a situação como uma oportunidade para aprender e desenvolver novas competências, tentar pensar em si como um vencedor. A segunda traz um olhar mais pessimista quando propõe como ações: antecipar as consequências para se preparar para o pior, delegar o trabalho a outros, aceitar a situação, porque não há nada que se possa fazer para modificar. A terceira estratégia apresenta certo grau de aniquilamento em algumas ações que acontecem em excesso, pois exemplifica como gestão de sintomas: ingerir bebidas alcoólicas, tomar tranquilizantes, sedativos ou outros medicamentos, comer, ver televisão, fumar.

Através de seus estudos, Pocinho e Capelo (2009) concluíram que professores autoeficazes se utilizam do primeiro tipo de estratégias citadas anteriormente, ou seja, as de controle. Essas ações reduzem as expectativas de fracasso e corroboram com a crença de que se pode exercer controle diante de situações adversas e complicadas.

Nóvoa (2007a) em ocasião de uma palestra proferida a educadores/as, a convite do Sinpro/SP, abordou os desafios do trabalho do professor no mundo contemporâneo e defendeu uma nova identidade profissional, a fim de abrandar os paradoxos da profissão concernentes às atribuições de missões, do desprestígio docente e a inexistência de condições de trabalho concretas. Dessa forma, este autor defende que o compromisso ético dos/ as professores/a seja a construção de uma escola centrada na aprendizagem, posicionando os alunos/as em um patamar comum de conhecimentos. Outro ponto, segundo o autor, é que a escola seja como a sociedade (com regras de vida em comum, de diálogos) e também que a mesma seja vista como uma instituição (não como prestadora de serviços, e sim como um lugar onde se institui a sociedade, a cultura, a pessoa).

As questões referentes à professoralidade são trazidas por Nóvoa (2007a) como desafios para o futuro, uma vez que deve haver uma (re)organização da profissão, uma formação centrada nas práticas e a credibilidade da profissão. Esse autor motiva os/as educadores/as quando diz que "[...] nada substitui o bom senso, a capacidade de incentivo e de motivação que só os bons professores conseguem despertar. Nada substitui o encontro humano, a importância do diálogo, a vontade de aprender que só os bons professores conseguem promover." (NÓVOA, 2007a, p. 18). Essa fala produz sentimentos motivadores para o campo da Educação, uma vez que instiga os docentes a superarem os desafios vindouros com maior positividade.

Ao escrever Vida de Professores, Nóvoa (2007b) refere-se às abordagens (auto) com, enfrentar, ultrapassar, dar resposta a, reagir a circunstâncias adversas. biográficas no campo científico, como um movimento social que se utiliza de métodos 
biográficos, autoformação e biografias educativas, já que as histórias de vida dão origem a práticas e reflexões de caráter interdisciplinar e de recursos conceituais e metodológicos. $\mathrm{O}$ autor propõe a categorização das histórias de vida baseada nos objetivos e nas dimensões que as abordagens privilegiam. Dessa forma, Nóvoa (2007b) acredita que as histórias de vida contribuem para a elaboração de novas propostas sobre a formação de professores e sobre a profissão docente.

Sampaio, Stobäus, Mosquera e Jesus (2012) objetivaram, a partir de dados de situações de mal-estar docente, colocar em prática uma intervenção com um grupo de professores da Educação Básica, através de oficinas. Este trabalho consistiu numa tentativa de propiciar condições de reflexões sobre as práticas e posturas docentes, tanto na vida pessoal como profissional, que conduzisse os/as educadores/as em direção ao bem-estar docente. De acordo com esses autores, cada professor/a, dependendo da forma como percebe a situação, lida de maneira diferente com as situações de mal-estar: "O grau de mal-estar docente depende da forma como lida com potenciais fontes de mal-estar, podendo esta forma de lidar ser aprendida." (SAMPAIO et al., 2012, p. 5). Essa aprendizagem pode acontecer nas formações educacionais e nos encontros de educadores/as - quando há o desenvolvimento de qualidades e competências já existentes, agregando estratégias de coping e capacidade de resiliência, a fim de contribuir para o bem-estar docente.

Um dos pontos trabalhados pelos autores na proposta refere-se às questões ligadas à autoimagem e à autoestima docentes. Essas dimensões de cuidado de si dizem respeito aos aspectos físicos, mentais e espirituais, os quais muitas vezes são deixados de lado em detrimento de tantos afazeres que absorvem o cotidiano dos/as professores/as. Após as intervenções feitas, os autores constataram uma nova visão dos sujeitos quanto à própria saúde, seja na prática de exercícios físicos, seja na alimentação saudável ou no tratamento de enfermidades que eram relegadas a segundo plano.

Timm, Mosquera e Stobäus (2010, p. 874) advertem para a necessidade do/a professor/a não desistir de cuidar de si, em tempos de liquidez moderna7: "Pelo contrário, quando tudo parece dizer-lhe não ou estar a confundir seus projetos, é preciso que reassuma o comando de si mesmo." Nessa perspectiva, os/as professores/as devem (re)construírem-se diariamente, num movimento de desacomodação, evitando, dessa forma, sentimentos de autopiedade e valorizando-se, numa postura de amor próprio. Os autores supracitados argumentam que a autoestima é decorrente da autoimagem e que ambas são processos permanentes e contínuos da construção da personalidade humana, sendo necessário um olhar mais atento a essas questões, a fim de se proteger da perversidade existente na era atual.

Teixeira (2007) trata da condição docente como uma relação. Segundo esta autora,

A docência se instaura na relação social entre docente e discente. Um não existe sem o outro. Discentes e docentes se constituem, se criam e recriam mutuamente, numa invenção de si que é também uma invenção do outro. Numa criação de si porque há o outro, a partir do outro. (TEIXEIRA, 2007, p. 429).

É, portanto, uma relação instaurada entre sujeitos socioculturais, cada qual com sua história de vida, sua bagagem cultural e emocional, enfim, com suas experiências. Entre tantas relações distinguidas pela autora, há a dimensão do cuidar, isto é, do zelo para consigo e para o outro, da ética e da estética, do respeito e da alteridade.

Como sujeitos socioculturais, os/as professores/as e os/as estudantes constroem-se a partir da troca de conhecimentos, sendo que esta construção não é estanque, não acontece em níveis. Nesse entendimento, a aprendizagem é construída de forma dialética, através da interação entre indivíduos e o meio externo. A curiosidade e o interesse em aprender vêm do outro que possibilita estas questões, vêm do docente que em sua condição de bem-estar, em sua autêntica professoralidade envolve, desafia e, assim, torna o conhecimento algo
7 > Expressão utilizada por Zigmund Bauman sobre a atual época da líquida modernidade, na qual as pessoas procuram sentido, mas ao mesmo tempo não querem se prender às suas próprias identidades. 
convidativo, provocador e relevante aos/às alunos/as - conforme os estudos de Aguiar Jr. (2010). Este autor destaca que não basta analisar a sequência de atividades de um projeto ou a qualidade das mesmas, "[...] mas ainda o modo como as atividades são conduzidas nas interações entre professor e estudantes nas salas de aula em movimentos coletivos de construção de sentidos." (AGUIAR JR., 2010, p. 720).

Nessa perspectiva de uma reinvenção de práticas e ressignificação de conteúdos, o/a docente vai construindo sua autoestima e conferindo autonomia aos/às estudantes, por meio do desenvolvimento de situações de interação, nas quais os/as alunos/as podem exercer sua autonomia, na medida em que expõem suas vontades, suas perspectivas acerca de um determinado assunto. Há, portanto, uma significativa produção de sentido e bem-estar, tanto para os docentes quanto para os discentes que compartilham dessas interações discursivas produtivas.

Nessa assertiva, a estrutura das histórias permite essa reorganização interna de sentimentos e de soluções de problemas, pois constitui-se, geralmente, de quatro partes: situação inicial, conflito, processo de solução, sucesso final. Para a resolução dos conflitos, os personagens munem-se de estratégias para resolvê-los, desenvolvendo suas capacidades e inteligências, de modo a solucionar e concluir com sucesso suas desventuras narrativas. Conforme Aguiar (2009, p. 79) essa estrutura ajuda as crianças a organizarem suas percepções e "[...] a vivenciar e resolver emoções que lhe parecem complexas e de difícil compreensão.”. Estendemos estes benefícios aos adultos, no caso, aos docentes e discentes.

A contação de histórias, com suas inúmeras possibilidades de interação, de identificação e sensibilização, envolve o ser humano e pode ser utilizada como método que auxilie os professores a formular estratégias de coping, servindo como ponte para a promoção de bem-estar.

\section{O enredo da história: caminhos percorridos}

A metodologia escolhida para este estudo foi a de abordagem qualitativa e foi pautada pelo relato de experiência advindo de três práticas distintas, cujas reflexões teóricas, referidas acima, servem de fundamentação para as articulações pretendidas sobre a contação de histórias como manifestação literária e como produtora de situações de bem-estar docente.

A primeira prática ${ }^{8}(\mathrm{P} 1)$ teve como público-alvo 25 professoras do Bloco de Alfabetização, isto é, docentes dos $1^{\circ}, 2^{\circ}$ e $3^{\circ}$ anos do Ensino Fundamental, que escolheram esta entre outras oficinas oferecidas em uma Escola Municipal de Canoas. O trabalho abrangeu aproximadamente duas horas e ocorreu em agosto de 2012, no evento intitulado I Sábado Pedagógico: Saberes e Fazeres na Alfabetização, um programa da rede municipal de Canoas, na Formação Continuada de Professores. Optamos pelo formato de oficina, para que as professoras pudessem interagir e se movimentar durante as dinâmicas propostas, cujo enfoque foi um novo olhar sobre a prática literária da contação de histórias nas salas de aula.

A segunda prática (P2), devido à Formação Continuada de Professores, contou com o público-alvo de 27 professoras, das quais doze eram professoras da Educação Infantil e quinze, do Projeto Pedagógico Alternativo (PPA), da rede municipal de Canoas, e ocorreu durante quatro horas. O evento aconteceu em setembro de 2012, no auditório da Secretaria

$8>$ A partir deste momento, apresentaremos os trabalhos realizados com as iniciais $\mathrm{P}$ para Prática, enumerando a primeira P1 e consecutivamente P2 e P3, D para docentes e E para estudantes graduandos do Curso de Letras. Municipal da Educação, cuja pauta, desenvolvida também na P1, especificamos abaixo:

" Preparação para a contação de histórias: ritual, motivação, aspectos sensoriais;

» Exemplos de contação de histórias: A casa e A princesa que queria ser bonita, textos presentes na antologia de William J. Bennett;

»Diferença entre o ler e o contar histórias: adaptações e reconstruções na sala de aula; 
» A contação de histórias como atividade transformadora. Teóricos abordados: Vigotski (1998), Zumthor (2007) e Aguiar (2009);

" Dinâmicas: contando nossas histórias; percebendo o outro; sequência textual; dramatização.

A dramatização foi o ponto-chave das oficinas, pois as professoras permitiram-se, como será relatado adiante, vivenciar a magia de fazer parte de uma história. Na P1, a história encenada foi Lúcia Já-Vou-Indo, de Maria Heloísa Penteado, na qual uma lesma é convidada para uma festa, contudo, movimenta-se vagarosamente e acaba chegando muito atrasada, como ocorre toda vez que recebe convites. Até que um dia, Chispa-Foguinho, uma libélula bem articulada, tem a ideia de fazer com que Lúcia participe dos eventos, sendo ela mesma a anfitriã. Assim, se Lúcia não consegue ir à festa, esta ocorre em sua casa.

$\mathrm{Na}$ P2, aconteceu a encenação da história A corujinha branca, de Tracey Corderoy e Jane Chapman, a qual narra a vida de uma coruja sem nome que mora em meio a neve. Um dia ela resolve sair pelo mundo a procura de novos lugares e encontra árvores cheias de cores, que num primeiro momento parecem joias, mas, quando aproxima-se, percebe que são corujas de todas as cores. Estas, por sua vez, repelem a corujinha branca, alegando que, como ela não tem cor, não pode pertencer àquele grupo. Para integrar-se, a coruja propõe a contação de suas histórias, repletas de aventuras e fantasia. As corujas multicores ficam encantadas com as narrativas e resolvem conhecer o lugar onde vive a nova amiga e vivenciar suas aventuras. Assim, tornam-se amigas, unidas pelas histórias de suas vivências.

Quanto à terceira prática (P3), esta envolveu dez alunos da graduação de Letras (sendo quatro alunos e seis alunas) e um professor e uma professora atuantes no curso, durante aproximadamente três horas. Esta atividade ocorreu em novembro de 2012, no miniauditório de uma Instituição de Ensino Superior (IES) de Canoas, em decorrência da Semana Acadêmica do Ensino Superior. A princípio, o formato seria uma palestra, entretanto, optamos por uma oficina intitulada Literatura infantil: ênfase na contação de histórias, para que teoria e prática se entrelaçassem, assim como nas duas práticas anteriores. Nessa oficina, a pauta sofreu alterações devido ao tempo destinado à dinâmica 'contando nossas histórias', na qual os/as alunos/as relataram suas histórias de vida, suas expectativas quanto à profissão e quanto ao ser professor com facilidade de expressar suas ideias, denotando liberdade de expressão, desinibição e vontade de falar.

\section{Os personagens protagonistas e seus discursos}

Com o intuito de estabelecer conexões entre a teoria e a prática, relatamos a seguir os discursos dos/as participantes envolvidos nas atividades propostas. Nas três práticas, o processo inicial foi semelhante. Após a contação da história $A$ casa (escolhida para abordar a questão do trabalho mútuo, do esforço dispensado às atividades físicas e mentais, do prazer de se fazer um trabalho bem feito), propusemos a dinâmica 'contando nossas histórias'. Colocamos uma caixa cheia de objetos (relógio, livro, agenda, dicionário, perfume, jogos, celular, carteira, brinquedos, medicamentos, material escolar etc.) no centro dos grupos e pedimos que cada um/a escolhesse um objeto com o qual se identificasse. As professoras da P1 demoraram um pouco para se levantarem e escolherem os objetos.

Abstivemo-nos de qualquer comentário, pois nosso objetivo foi observar e perceber como lidavam com a situação proposta. As docentes demonstraram certa falta de vontade e insegurança na escolha do objeto, como nos comentários a seguir (salientamos que os registros foram coletados através da transcrição das falas gravadas em áudio):

Acho que vai faltar coisa. Não vai ter pra todo mundo (D20). É pra pegar qualquer um?(D7). Não tem nenhum que me identifique, mas vou pegar esse mesmo (D9). 
O mal-estar já se pronunciava antes mesmo de se iniciar o diálogo entre os pares. Após escolherem os objetos, voltaram aos seus lugares. Nós estávamos sentadas junto a elas no círculo e pedimos que alguém iniciasse sua fala, contando suas histórias a partir do objeto escolhido. Após o desconforto inicial, uma professora perguntou:

É pra falar o quê? Meu nome, onde trabalho, pra que turmas dou aula? (D1). A professora sentada ao lado ajudou: Conta um pouco de ti, por que tu escolheste o objeto, o que tu fazes... (D2).

Os relatos focaram mais as questões profissionais, sobretudo, questões de horários, turmas, demanda de trabalho. Pouco falou-se do aspecto pessoal, da família, das perspectivas e dos sonhos:

Escolhi o relógio porque estou sempre correndo contra o tempo. Trabalho 60h e não tenho tempo para fazer cursos, me atualizar (D6). Sempre procuro fazer do limão uma limonada, uso as ferramentas que tenho e tento trabalhar da melhor maneira possível (D10). As turmas são cheias e fica difícil fazer um bom trabalho (D13). Peguei o quebracabeça porque minha vida é um, tenho que me virar em muitas para dar conta de tudo o que tenho pra fazer (D25).

Após a dinâmica, contamos a história A princesa que queria ser bonita, cujo enredo emociona e provoca reflexões sobre o bem que se faz ao outro, sobre a alegria de ajudar alguém a se sentir melhor, a encontrar um caminho, enfim, sobre a beleza que se carrega dentro de si e que é vista pelo outro. As professoras emocionaram-se com a narrativa, cada uma da sua maneira. O desconforto inicial deu lugar a uma leveza, a um compartilhamento de emoções claramente percebidas, uma vez que a contação de histórias acontece através do olhar, dos gestos e, como contadoras, percebemos que as docentes se identificaram com a história e a má vontade deu lugar ao encantamento.

$\mathrm{Na}$ dinâmica final, as participantes foram convidadas a encenar a história Lúcia Já-Vou-Indo, de Maria Heloísa Penteado, que conta a história de uma lesma que não conseguia chegar a tempo aos eventos sociais (festas, aniversários, casamentos). A protagonista não poderia ter sido mais perfeita. Enquanto a história era narrada, ela fazia sua performance de um jeito muito divertido, pois agia exatamente como uma lesma. As demais personagens também demonstraram excelente atuação, manifestaram prazer em colaborar e estavam contentes por vivenciar a narrativa em grupo.

Ao término da oficina, notamos que a comunicação realizada provocou transformações, algumas superficialmente detectadas, outras transcritas nos relatos a seguir:

Minha intenção era sair mais cedo pra fazer um monte de coisas em casa. Mas fui ficando, ficando e gostei muito. Obrigada! (D12). Eu não costumo gostar desses cursos de formação, mas esse foi diferente. Eu gostei bastante (D7). Que bom saber que tu és professora como nós. Eu adorei a manhã de hoje e adorei te conhecer(D13). Quando fizeres outras formações, me avise. Estou me sentido feliz. Parabéns! (D21).

$\mathrm{Na}$ P2, a pauta de trabalho foi a mesma, sofrendo algumas alterações quanto às dinâmicas. Contudo, as professoras utilizaram melhor o tempo para contar suas histórias e houve claramente sinais de mal-estar presente nas falas das docentes que trabalham com os anos iniciais do Ensino Fundamental, conforme os discursos a seguir:

Tenho 24 anos de Magistério, estou me aposentando no ano que vem. Trabalho com 18 turmas no PPA e trabalho também com o Ensino Médio, com os alunos que saem da EJA (Educação de Jovens e Adultos) das escolas públicas da região de Canoas. Esses alunos são semianalfabetos. Vejo que no PPA os alunos adoram ler, estão sempre com um livro na mão, mas na hora de produzir é triste. Com a nova lei não há mais reprovação, as professoras vão ter que dar conta (D4).

Eu queria pegar uma boneca (da caixa de objetos), mas quando cheguei não tinha. Eu pensei na afetividade, no aconchego, por isso a boneca em função das crianças. Daí eu substituí pelo macaquinho porque os animaizinhos também precisam de atenção e carinho. 
A maioria dos problemas que a gente enfrenta é em função da carência do nosso aluno. A rejeição e revolta que eles têm não é com a gente (D6).

Eu escolhi o relógio por questão de pontualidade, de que cada dia a gente tem menos tempo na vida. Em vez de 24 h a gente tinha que ter 48 h. A vida vai passando e cada vez temos menos tempo (D11).

Eu peguei um pen-drive, porque a pen-drive tem sido tudo pra mim. Eu carrego a minha vida aqui. Tenho muitas turmas, o trabalho é cansativo (D12).

Eu fui uma das últimas a chegar na caixa e vi a Bíblia. Achei muito interessante isso porque é aqui (na Bíblia) que eu busco todos os dias... (A professora emociona-se e chora. Fica com a fala engasgada, mas reinicia sua fala). Eu trabalho com o PPA e é um desafio em razão da clientela diferente da escola em que eu trabalhava há 8 anos. Eu achei que eu não ia conseguir. Mas agora eu já sou amada por eles (D15).

Apesar de eu ser formada em Letras - Português/Inglês eu tenho turmas do $1^{\circ}$ ao $5^{\circ}$ ano à tarde com o PPA. É uma experiência nova, não é muito a minha área, mas estou trazendo um pouco de Inglês pra eles, através de musiquinhas (D19).

Eu estou sempre garimpando trabalhos diferentes. Eu vim à oficina para aprender, para ter algum trabalho que eu possa utilizar nas aulas. A gente precisa sempre ter uma cartinha na manga para atender aquele aluno que a gente encontra todo dia. Ontem chegou um aluno de São Paulo, a essa altura do ano, no $2^{\circ}$ ano, não alfabetizado. O que eu vou fazer? (D20).

Esses relatos fizeram parte da primeira dinâmica da oficina, isto é, ocorreram antes da exposição da teoria, da conversa e da contação de histórias. Os sintomas de mal-estar permeiam as falas das professoras e se referem às questões presentes nos estudos de Nóvoa (2007a), Teixeira (2007), Timm, Stobäus e Mosquera (2010), Sampaio, Stobäus, Mosquera e Jesus (2012), como a demanda de trabalho, as missões, o tempo, o número de alunos e de turmas em excesso, trabalho fora da área de atuação, as diversidades, o enfraquecimento físico, psíquico e espiritual.

Por outro lado, os discursos das professoras das Escolas Municipais de Educação Infantil (EMEI) são mais otimistas e alegres. Elas pareceram seguras de suas escolhas, de suas carreiras e do trabalho diário com as crianças pequenas. Em suas falas, é possível perceber que a contação de histórias está mais presente na rotina de trabalho do que no cotidiano das professoras dos anos iniciais:

Faz 4 meses que trabalho no berçário de uma EMEI. Eu escolhi o bloco lógico pensando que todo mundo já tentou montar um e o que conta é a persistência e eu acho que isso vale muito na vida da gente. Outra relação é que quando a gente leva um objeto pra contação de histórias, principalmente no berçário, a criança se interessa mais. Eu conto histórias uma vez por semana e fiz um boneco chamado Zé Contador de Histórias. Ele vai contando as histórias e as crianças vão pegando. É um objeto que eu trago junto com a contação de histórias (D9).

Escolhi o chá de frutas eflores por ser um chá misto e eu acredito que não só o professor, mas o ser humano em si é um ser holístico de muitas potencialidades. E o professor tem sempre que buscar uma diversidade tanto na vida pessoal e na vida profissional principalmente, porque a demanda está vindo cada vez maior pra gente atender a essas crianças da nova geração (D13).

Eu falo muito. Falo mesmo. Não precisa ter um livro na minha mão. É algo meu com as crianças. Através de uma história eu acabo dando uma aula. É algo muito habitual na minha vida. Eu não precisei ser professora pra isso. Escutar uma história é ótimo. Contar é melhor ainda porque tu sabe que alguém está te escutando (D7).

Eu escolhi este objeto (um colar havaiano) porque eu gosto muito do círculo. Eu acho que o círculo tem a ver com a cooperação, com os olhos nos olhos e isso é muito legal com as crianças. Eu também trabalho no berço (D18). 
Trabalho com o Maternal I e me identifiquei com a caixa de giz, que geralmente é o professor que usa, porque eu não me imagino fazendo outra coisa. Já estou na profissão há 28 anos (D2).

Apenas uma participante (que, inclusive, chorou durante seu relato) saiu da oficina antes do término, justificando que estava com um forte resfriado. As demais participaram ativamente das dinâmicas propostas, tecendo comentários elogiosos e conversando sobre suas práticas, bem como pedindo dicas para a contação de histórias.

Nesta P2, a história escolhida para dramatização, novamente, foi A corujinha branca, de Tracey Corderoy e Jane Chapman. As participantes interpretaram muito bem a narrativa, voaram como corujas, vivenciaram as aventuras contidas nas histórias da corujinha branca e vibraram. Riram bastante, demonstrando perceptível sensação de bem-estar por estarem fazendo parte da dinâmica.

Ao final da oficina, recebemos muitos abraços, sorrisos e elogios. A seguir, alguns comentários que consideramos relevantes para exemplificar as sensações produzidas:

Adorei a oficina. Vou contar a história da "Princesa que queria ser bonita" para meus alunos esta semana (D10). Lá na nossa escola estamos precisando desse entusiasmo, dessa motivação para encantar os alunos. Gostei muito dessa manhã. Por favor, me avise sobre próximas oficinas (D14). Parabéns pela oficina, Janaina. Tu falas de um jeito gostoso, bom de ouvir. Aprendi muito hoje e vi como contar histórias é simples e ao mesmo tempo proporciona tanta coisa (D25).

A P3 envolveu estudantes da graduação do curso de Letras de uma IES de Canoas. A pauta de trabalho sofreu algumas reduções em relação às oficinas anteriores, mesmo assim, não conseguimos abordar tudo o que havíamos programado, devido ao grande tempo dedicado ao momento do 'contando nossas histórias'. Os/As graduandos/as permitiramse falar sobre suas expectativas e perspectivas quanto ao curso escolhido, quanto ao ser professor e quanto às questões sociais que norteiam a educação. Para exemplificar, trazemos alguns excertos dos discursos:

Depois que comecei a ler a Bíblia e a falar sobre suas histórias fiquei desinibido e senti que as pessoas prestavam atenção em mim. Então resolvi cursar Letras para melhorar ainda mais minha fala e escrita e pretendo lecionar Português para os adolescentes, pois me identifico com essa faixa etária (E3).

Meu objetivo é ser ator, por isso escolhi o microfone. Quero cursar Artes Cênicas na UFRGS, mas penso que o curso de Letras vai me ajudar nas questões de escrita e oralidade, vou aumentar meu vocabulário e me expressar melhor (E9).

Escolhi esse curso porque gosto de lidar com pessoas e acredito no futuro do professor. Sei que o discurso é outro. O professor é desvalorizado, desmotivado, ganha pouco. Mas eu quero ensinar. Gosto do clima da sala de aula, de escola e acredito que o professor ainda será bem reconhecido (E5).

Sou ex-militar. Sempre gostei de ler histórias, principalmente as infantis, por isso escolhi esse livro. E hoje estou aqui, realizando meu sonho de estudar Letras (E10).

Eu escolhi este curso porque não quero trabalhar com as séries iniciais. Me identifico com os alunos maiores, pois quero trabalhar os conteúdos e sei que vou fazer um bom trabalho. Futuramente pretendo me especializar em Linguística (E1).

Depois das narrativas orais, exemplificamos o uso da contação de histórias de narrativas impressas, trabalhamos a teoria, ensinamos algumas técnicas e finalizamos com a história da Corujinha Branca, que provocou visíveis emoções, como olhos cheios de lágrimas, sorrisos e espanto.

As/Os graduandos/as agradeceram pela participação na oficina e saíram felizes pelos corredores acadêmicos, seguros de si e de suas escolhas profissionais.

De acordo com as práticas relatadas, permitimo-nos constatar que há semelhanças entre as práticas realizadas, todavia, há diferenças de suma importância como a questão 
da fala com liberdade na P3. Os sucintos relatos de vida e de experiência, bem como a insegurança sobre o que falar dos/as docentes da P1 (principalmente) sugerem situações de mal-estar docentes já instaladas, uma vez que os graduandos (ainda não docentes) demonstraram-se seguros de si, das suas escolhas e de suas visões de futuro.

\section{À guisa de conclusão, o desfecho da história}

Os discursos coletados durante as oficinas permitem distinguir situações de bem e mal-estar docentes instaladas no corpo docente atuante em níveis e projetos diferenciados de ensino. Primeiramente, destacamos que a desmotivação demonstrada pelas professoras participantes da $\mathrm{P} 1$ pode ter decorrido em virtude da oficina acontecer em um sábado pela manhã e, também, por tratar-se de uma Formação Continuada oferecida pela rede de ensino. Constatamos que, antes mesmo de saberem do que se tratava, já apresentam falta de vontade e desinteresse e, em suas contações de histórias, relataram o mal-estar subjacente às suas práticas diárias em sala de aula com alunos dos anos iniciais do Ensino Fundamental. Outra questão inerente é o fato dessas professoras pertencerem ao Bloco de Alfabetização instituído recentemente, cujo cerne é a não retenção do aluno nesses três anos escolares. Sendo assim, os/as alunos/as poderão se alfabetizar gradualmente durante esse período, o que acarreta um visível mal-estar diante da problemática da não alfabetização no $1^{\circ}$ ano (ou como anteriormente instituída, a $1^{a}$ série).

As participantes da P2 demostraram mais alegria e motivação, principalmente, as docentes da Educação Infantil. A contação de histórias está presente em seu trabalho diário com as crianças pequenas e seus discursos são repletos de segurança quanto à escolha profissional e ao trabalho em si. Por outro lado, as professoras que atuam no PPA relataram queixas a respeito do número elevado de turmas, do pouco tempo disponível, do trabalho fora da área de atuação e dos desafios enfrentados.

Os/As estudantes participantes da P3 demonstraram facilidade de expressar suas histórias ao grupo. Falaram de sua vida pessoal, suas visões de futuro profissional e crenças na condição de ser professor como profissional importante à sociedade e merecedor de valorização.

Durante as três práticas foi possível verificar uma mudança positiva nos semblantes, nas atitudes e nas falas produzidas após a contação de histórias: a de si mesmos, as coletivas e a narração das histórias impressas. Isso ocorreu porque o contar histórias consiste em um ato de comunicação que permite a prática dinâmica de trocas simbólicas, imaginárias e reais, através do diálogo estabelecido entre o contador e o ouvinte. As palavras narradas interagem com o universo vocabular do espectador, proporcionando possíveis relações e significações.

Os discursos coletados, em consonância com os diversos teóricos estudados, permitem considerar que há estreita relação entre a prática da contação de histórias e o desencadeamento de situações promotoras de bem-estar.

Conforme Zumthor (2007), o recebimento de uma comunicação acarreta uma transformação. As histórias, como situações comunicativas, despertam o interesse, a curiosidade, a identificação e, assim, transformações, sejam físicas, emocionais, psíquicas, espirituais. Ao utilizar-se do simbolismo e da linguagem existentes em seu corpo e em sua voz, o narrador estimula a troca de emoções inerentes à identificação com as experiências alheias.

Collins e Cooper (2005) chamam de encantamento a convergência entre a história, a contação e o ouvinte. Dessa maneira, a partir de seu caráter estético e artístico a narração/ contação de histórias configura-se como um veículo sóciodialético, ou como referimos no título deste trabalho, um caminho que pode guiar os/as docentes a situações de bem-estar e, consequente encontro de produções de sentido para a docência e para a vida.

Apontamos que o uso da contação de histórias nos espaços de formação docente pode se constituir como caminho para o sentir-se bem, para a motivação, para o cuidado 
consigo (a partir dos processos de autoimagem e autoestima), uma vez que a interação sóciodialética estabelecida contribui para o desenvolvimento desses processos de percepção de si mesmo e do outro.

\section{Referências}

AGUIAR, Vera Teixeira de. (Coord.). Era uma vez... na escola: formando educadores para formar leitores. Belo Horizonte: Formato Editorial, 2009.

AGUIAR Jr., Orlando. A ação do professor em sala de aula: identificando desafios contemporâneos à prática docente. In. SANTOS, Lucíola et al. (Org.) Convergências e tensões no campo da formação e do trabalho docente. Belo Horizonte: Autêntica, 2010.

BAUMAN, Zigmund. Modernidade líquida. Rio de Janeiro: Zahar, 2001.

BENJAMIN, Walter. O narrador. In: Magia e técnica, arte e política: ensaios sobre literatura, história da cultura. Trad. Sérgio Paulo Rouanet. 7. ed. São Paulo: Brasiliense, 1994.

BENNETT, William John. A casa. In: O livro das virtudes. Rio de Janeiro: Nova Fronteira, 1995. p. 240.

BENNETT, William John. A princesa que queria ser bonita. In: O livro das virtudes II: o compasso moral. Rio de Janeiro: Nova Fronteira, p. 332. 1996.

COLLINS, Rives; COOPER, Pamela J. The power of story: teaching through storytelling. 2. ed. Illinois: Waveland Press, 2005.

CORDEROY, Trace; CHAPMAN, Jane. A corujinha branca. Tradução de Michele de Souza Lima. São Paulo: Ciranda Cultural, 2010.

COSTA, Sylvio de Sousa Gadelha. De fardos que podem acompanhar a atividade docente ou de como o mestre pode devir burro (ou camelo). Revista Educação e Sociedade. Campinas. v. 26, n. 93, p. 1257-1272, set./dez. 2005. Disponível em: <http://www.cedes.unicamp.br> Acesso em: 17 nov. 2012.

NÓVOA, António. Livreto: Desafios do trabalho do professor no mundo contemporâneo. São Paulo: SINPRO/SP, 2007a.

. História de vida: perspectivas metodológicas. In: NÓVOA, António (Org.). Vida de Professores. 2 ed. Porto: Porto Editora, 2007b.

PENTEADO, Maria Heloísa. Lúcia Já-Vou-Indo. São Paulo: Editora Ática, 2009.

POCINHO, Margarida; CAPELO, Maria Regina. Vulnerabilidade ao stress, estratégias de coping e autoeficácia em professores portugueses. Revista Educação e Pesquisa. São Paulo. v. 35, n. 2, p. 351-367, maio/ago. 2009.

SAMPAIO, Adelar Aparecido; STOBÄUS, Claus Dieter; MOSQUERA, Juan José Mouriño; JESUS, Saul Neves de. Efeitos de um Programa de Apoio ao Bem-Estar Docente na construção pessoal e profissional. Universidade de Caxias do Sul. Anais do IX ANPED SUL Seminário de Pesquisa em Educação da Região Sul, 2012. Disponível em < http://www.portalanpedsul.com.br/2012> Acesso em: 18 nov. 2012.

TEIXEIRA, Inês Assunção de Castro. Da condição docente: primeiras aproximações teóricas. Revista Educação \& Sociedade. Campinas. v. 28, n. 99, p. 426-443, maio/ago. 2007.

TIMM, Edgar Zanini; MOSQUERA, Juan José Mouriño; STOBÄUS, Claus Dieter. O mal-estar na docência em tempos líquidos de modernidade. Revista Mal-Estar e Subjetividade, Fortaleza: Universidade de Fortaleza, v. 10, n. 3, p. 865-885, set. 2010.

VIGOTSKI, Lev Semenovitch. Pensamento e linguagem. Tradução de Jefferson Luiz Camargo. 2. ed. São Paulo: Martins Fontes, 1998.

ZUMTHOR, Paul. Performance, recepção, leitura. Tradução de Jerusa Pires Ferreira e Suely Fenerich. São Paulo: Cosac Naify, 2007. 